\title{
The Mechanical Properties of Energetically Deposited Non-Crystalline Carbon Thin
}

\section{Films}

M. Kracica* (1), C. Kocer ${ }^{(4)}$, D. W. M. Lau ${ }^{(1)}$, J. G. Partridge ${ }^{(1)}$, J. E. Bradby ${ }^{(2)}$, B. Haberl ${ }^{(3)}$, D. R. McKenzie ${ }^{(4)}$ and D. G. McCulloch ${ }^{(1)}$.

(1) School of Applied Sciences, RMIT University, VIC 3001, Australia.

(2) Department of Electronic Materials Engineering, Research School of Physics and Engineering, The Australia National University, ACT 2601, Australia.

(3) Chemical and Engineering Materials Division, Neuron Sciences Directorate, Oakridge National Laboratories, Oakridge Tennessee 37831, USA.

(4) School of Physics, The University of Sydney, NSW 2006, Australia.

\begin{abstract}
The mechanical behaviour of carbon films prepared with a variety of densities and microstructures was investigated using nanoindentation. Deposition energies between 25 and $600 \mathrm{eV}$ and temperatures in the range $25-600^{\circ} \mathrm{C}$ were used. Films prepared at low temperatures and moderate energies were amorphous with a high density. Finite element methods were used to model the stress fields, reproduce the indentation behaviour and evaluate elastic properties. Young's moduli up to $670 \mathrm{GPa}$ and a low Poisson's ratio of $\sim 0.17$ were found, comparable to polycrystalline cubic boron nitride, one of the hardest materials known. Films with the same density did not always show the same behaviour, emphasising the role of microstructure in determining mechanical response. Extended graphite- like regions within the films grown at high energy and high temperature, observed in transmission electron microscopy caused plastic deformation and failure to recover after a complete
\end{abstract}


indentation cycle. At low deposition energies, the graphite-like regions were smaller in size causing plastic deformation but with complete recovery after indentation.

\section{Introduction}

Carbon coatings exhibit wear-resistance, low-friction, bio-compatibility and high durability in chemically harsh conditions [1-4]. The main application for non-crystalline carbon thin films is in wear protection [1, 4-6]. If the microstructure contains a high proportion of diamond-like $\left(\mathrm{sp}^{3}\right)$ bonds, the film is dense and mechanically hard. For example, tetrahedral amorphous carbon (ta-C) is an amorphous form of carbon with up to $85 \% \mathrm{sp}^{3}$ bonds and is one of the hardest known covalent network solids [7]. In contrast, films containing a low fraction of $\mathrm{sp}^{3}$ bonds show a lower modulus but exhibit a high degree of elastic recovery from large deformations [4]. This property, also observed in glassy carbon [ref] and hard carbon [ref] (both non-graphitising carbons with tangled graphitic microstructure) is known as aneslasticity $[8,9]$. Anelasticity arises from the fact that the graphene sheet is the strongest two dimensional structure known and can exhibit a shape memory effect [10]. In terms of non-crystalline carbon films, the relationship between the microstructure and any recovery is not presently understood.

There is a wide variability in the reported elastic modulus (100- $800 \mathrm{GPa}[4,11-13]$ ) and hardness (5- $80 \mathrm{GPa}[4,11-13])$ of non- crystalline carbon films, with the latter based largely on empirical models. In general, it has been reported that the hardness and/or modulus of carbon films correlates simply with the fraction of $\mathrm{sp}^{3}$ bonds or density $[4,14,15]$. However, the microstructure and in particular the arrangement of any layered graphitic structures, may also influence the mechanical properties. There is currently no detailed study of the relationship between microstructure and mechanical properties in non-crystalline carbon thin 
films. This knowledge would enable the selection of carbon coatings optimised for particular tribological applications.

Here, we investigate the mechanical properties of non-crystalline carbon films with different densities and microstructures. The film characteristics were controlled by adjusting the average energy of the depositing flux and the growth temperature within a filtered cathodic vacuum arc (FCVA) deposition system $[16,17]$. The microstructure of the films was characterised using transmission electron microscopy (TEM) and electron energy loss spectroscopy (EELS). Nanoindentation was used in combination with Finite Element Modelling (FEM) to probe the mechanical properties of the films. Measurements of the reduced elastic modulus, average energy dissipation and residual penetration depth following indentation revealed the relationships between the mechanical properties, density and microstructure of the films.

\section{Method}

Carbon films were deposited using a FCVA system equipped with a double bend magnetic filter to minimise the incorporation of macro particles into the growing film. A base pressure of less than $2 \times 10^{-5}$ Torr was established before each deposition. These were performed by ablating the $99.9 \%$ pure graphite source with an arc current of $\sim 60$ A. Films with thicknesses between 100 and $150 \mathrm{~nm}$ were deposited onto n-type conductive $6 \mathrm{H}-\mathrm{SiC}$ and $\mathrm{Si}$ substrates. Previous nanoindentation experiments performed on carbon films supported by $\mathrm{Si}$ revealed that the Si deformed significantly under moderate loads [18]. $6 \mathrm{H}-\mathrm{SiC}$ was chosen here as a precautionary measure due to its relatively high elastic constant (400 GPa) and because no phase changes occur during indentation (unlike in $\mathrm{Si}$ [19]). Samples were mounted onto a bias compatible substrate heater/holder, and depositions were performed using biases from $0 \mathrm{~V}$ (earthed) to $600 \mathrm{~V}$ and substrate temperatures from $30^{\circ} \mathrm{C}$ to $600^{\circ} \mathrm{C}$. 
The depositing carbon flux in the FCVA system is fully ionised $[16,17]$ so the average deposition energy can be determined from the bias voltage, average charge state of the plasma (1+ for carbon [16]) and the energy of the carbon flux (measured to be $\sim 20 \mathrm{eV}$ in our system [16]).

The microstructure of the films was studied using a JEOL 2010 TEM operated at $200 \mathrm{kV}$. EELS was performed using a Gatan imaging filter to obtain the mass density. Films were prepared for TEM by sacrificially etching the Si substrates. A cross-section TEM sample of one of the films was also prepared by mechanical polishing and ion beam thinning. Low loss EELS spectra were collected from each film and deconvoluted for multiple scattering using the Fourier log method. The sample densities were calculated from the plasmon peak positions, assuming a free electron model with four valence electrons and an effective mass of $0.88 \mathrm{~m}_{\mathrm{e}}$ (where $\mathrm{m}_{\mathrm{e}}$ is the electron mass at rest) [16, 20,21].

Nanoindentation experiments were performed using a Hysitron TI-950 nanoindenter fitted with a Berkovich tip. The effective radius of the tip, measured using a scanning electron microscope, was $\sim 220 \mathrm{~nm}$. A maximum load of $200 \mu \mathrm{N}$ was applied using loading/unloading segment times of $10 \mathrm{~s}$ to produce load-displacement curves [22]. The maximum load was chosen to ensure the maximum penetration depth was $<15 \%$ of the film thickness to minimise substrate effects [23]. No hold period at maximum load was used to avoid recovery effects due to the anelasticity of the films. Due to this behaviour, the standard Oliver- Pharr method for measuring the hardness and modulus of the films was not applicable [24-26]. Instead, the following analyses were applied in the purely elastic regime. The initial loading portion (up to $\sim 50 \mu \mathrm{N}$ ) was fitted using the Hertzian equation [22, 25, 27] to calculate the 
reduced elastic modulus $\left(E_{r}\right)$. For the plastic-elastic behaviour, the energy dissipation $\left(E_{d}\right)$ during indentation can be extracted using:

$$
E_{d}=\left(U_{\text {load }}-U_{\text {unload }}\right) / U_{\text {load }}
$$

where $U_{\text {load }}$ and $U_{\text {unload }}$ are the areas under the loading and unloading curves, respectively [24].

Finite element modelling was used to model experimental force-displacement curves for four representative carbon films with different microstructures. A 2-D axisymmetric model was constructed using the finite element software ANSYS [28]. Fig. 1a shows the FEM model used. The Berkovich tip was approximated with a spherical tip of radius $220 \mathrm{~nm}$, which is valid for small penetration depths. In the finite element model, the $\mathrm{SiC}$ substrate was $400 \times$ $400 \mathrm{~nm}$ with varying film thicknesses. In order to accurately model the indentation process and to optimise the finite element calculations, a mesh size of $<10 \mathrm{~nm}$ was refined. The indentation simulations were performed by applying loads of up to $200 \mu \mathrm{N}$ in the elastic regime. The values of Young's modulus (E) and Poisson's ratio (v) of the diamond indenter and $\mathrm{SiC}$ substrate were $1100 \mathrm{GPa}$ and 0.07 [29] and $400 \mathrm{GPa}$ and 0.19, respectively [30]. Estimates of $\mathrm{E}$ for the four carbon films were obtained from the experimental measurements of $E_{r}$ and values of $v$ between 0.19 and $0.28[4,11]$. These starting values of $E$ and $v$ were used in the FEM model in order to obtain an initial simulated load-displacement curve and then adjusted until the simulated load-displacement curve matched the initial part of the loading segment obtained experimentally. Fig. $1 \mathrm{~b}$ and $1 \mathrm{c}$ show contour plots of the hydrostatic pressure at maximum load for a high modulus $(\mathrm{E}=670 \mathrm{GPa})$ and low modulus $(\mathrm{E}=75 \mathrm{GPa})$ carbon film. The plots show that the stress field caused by the indentation is mainly contained within the thin film at the maximum experimental load $(200 \mu \mathrm{N})$. 


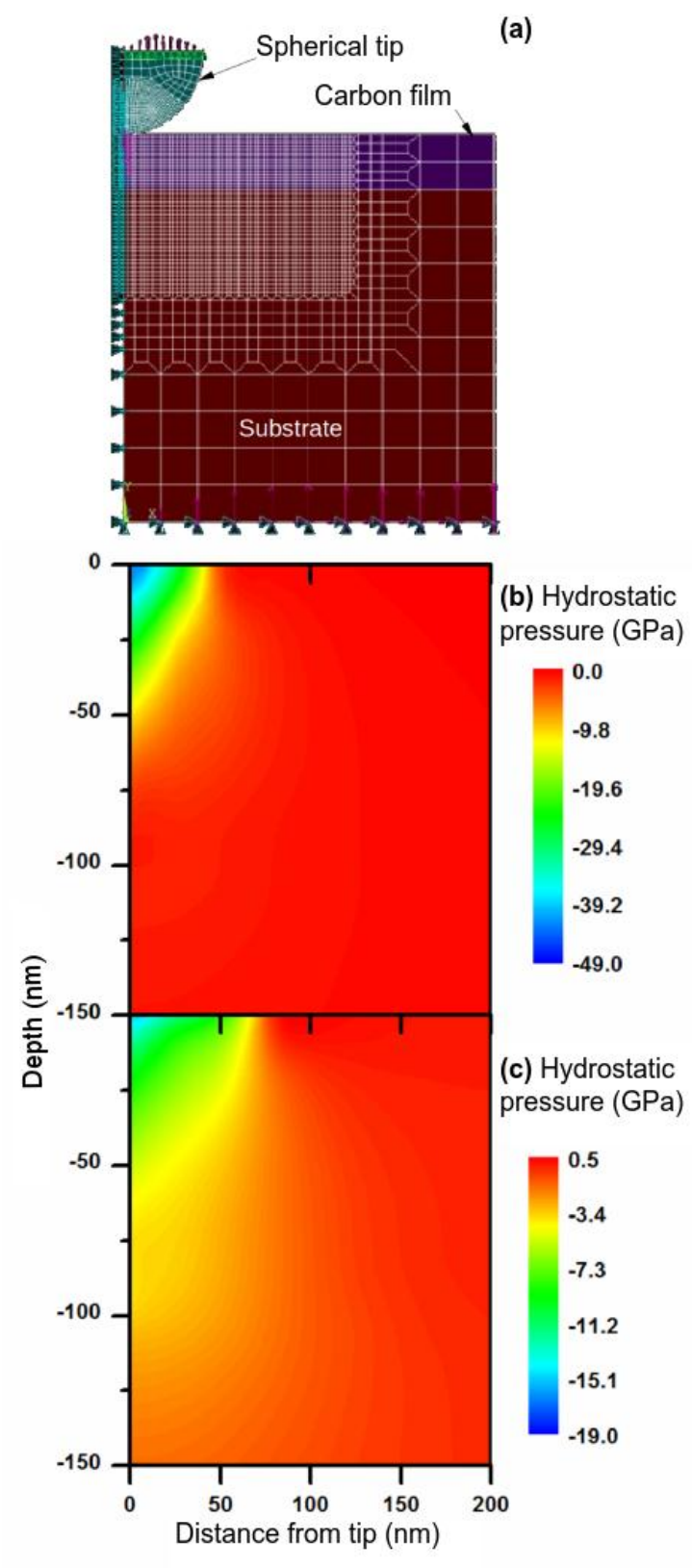

Fig. 1. (a) The FEM model used to simulate the indentation process. Two examples of the stress field for carbon films with (b) high modulus $(\mathrm{E}=670 \mathrm{GPa})$ and $(\mathrm{c})$ low modulus $(\mathrm{E}=75$ GPa) at the maximum load of $200 \mu \mathrm{N}$. 


\section{Results and Discussion}

Fig. 2a shows the density of FCVA-fabricated carbon films as a function of ion energy and substrate temperature. This contour plot is based on our previous work [16] and is included here to assist in showing the relationship between the density of the films and their mechanical properties. High density films are produced with ion energies of $50-400 \mathrm{eV}$ and substrate temperatures of up to $250^{\circ} \mathrm{C}$. This region corresponds to the conditions under which high compressive stresses lead to the formation of ta-C with densities up to $3.0 \mathrm{~g} / \mathrm{cm}^{3}$ [16]. The highest density material, which contains up to $\sim 85 \% \mathrm{sp}^{3}$ bonding, is formed when depositing onto a substrate at a temperature of $\sim 150^{\circ} \mathrm{C}$ and with ion energies of $\sim 95 \mathrm{eV}[16]$. It is well established that the microstructure of these high density films is amorphous $[7,16$, 31, 32]. In films deposited at room temperature, the density decreases at both high and low ion energies. At lower deposition energies, ions have insufficient energy to create the compressive stress required to form diamond-like bonds [16, 31, 32]. At higher ion energies, structural relaxations promote lower energy $\mathrm{sp}^{2}$ bonding and a lower density. The highest density material $\left(\sim 3.1 \mathrm{~g} / \mathrm{cm}^{3}\right)$ was formed at $\sim 150^{\circ} \mathrm{C}$ and ion energies between 100 and $200 \mathrm{eV}$. At temperatures above $\sim 250^{\circ} \mathrm{C}$, the film density $\left(\sim 2.2 \mathrm{~g} / \mathrm{cm}^{3}\right)$ is relatively insensitive to changing ion energy. This density is close to that of crystalline graphite and previous work has shown that these films have a high proportion of $\mathrm{sp}^{2}$ bonding [16, 32]. However, within this constant density region, a range of microstructures has been reported [4, 33-35]. 


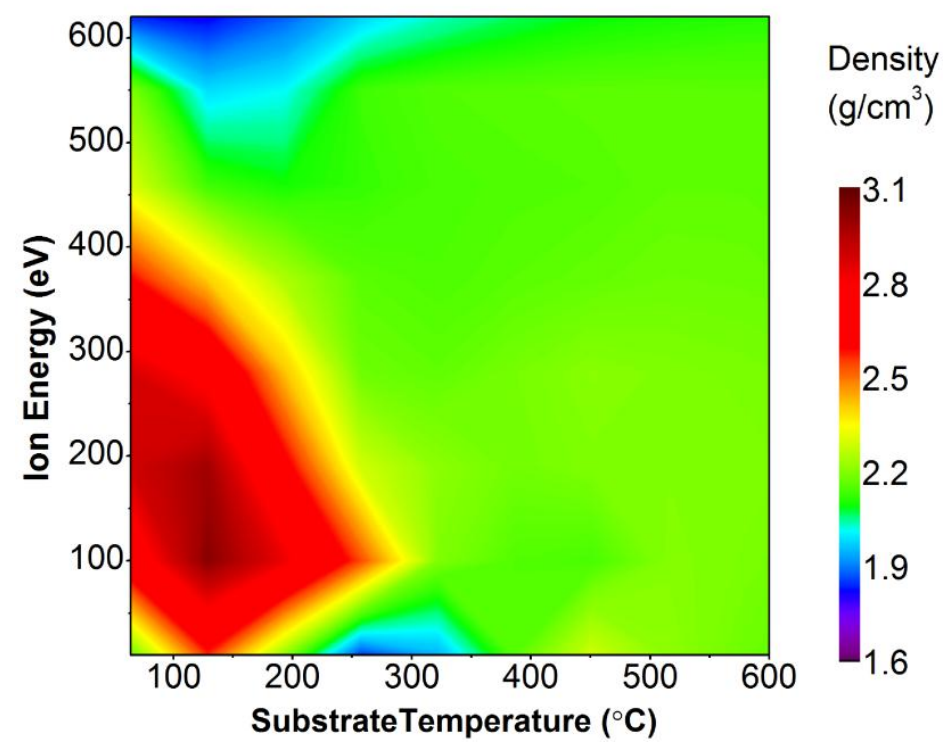

Fig. 2. Contour plot (adapted from [16]) showing the density of carbon thin films deposited from the FCVA as a function of average ion energy and substrate temperature.

Fig. 3a shows the load-displacement curves from samples prepared with $45 \mathrm{eV}$ ion energy at temperatures of 25,200 and $600^{\circ} \mathrm{C}$. The sample prepared at room temperature is ta-C with a density of $\sim 3.0 \mathrm{~g} / \mathrm{cm}^{3}$ (Fig. 2). The load portion of the curve overlays with the unload portion, showing that there was only elastic deformation with no significant plastic deformation. A $E_{r}$ of $370 \mathrm{GPa}$ was calculated from this curve. The recovery from the elastic deformation was complete, with no residual indent impression remaining. This type of elastic behaviour is typical of ta-C $[4,36]$. A lower $\mathrm{E}_{\mathrm{r}}(200 \mathrm{GPa})$ is calculated from the load portion of the curve from the sample prepared at $200^{\circ} \mathrm{C}$. Hysteresis exists between the load and unload curves and a very small residual indent impression remains at the completion of the cycle. When the deposition temperature was raised to $600^{\circ} \mathrm{C}, \mathrm{E}_{\mathrm{r}}$ decreases to $\sim 100 \mathrm{GPa}$ and the hysteresis increases. However, there is still little or no residual indent impression. The existence of load- unload hysteresis with no residual indent impression is characteristic of these samples and resembles the previously reported behaviour of glassy carbon [8]. 
The recovery was time dependent but in the cycle time used in these experiments $(20 \mathrm{~s})$, it was complete.
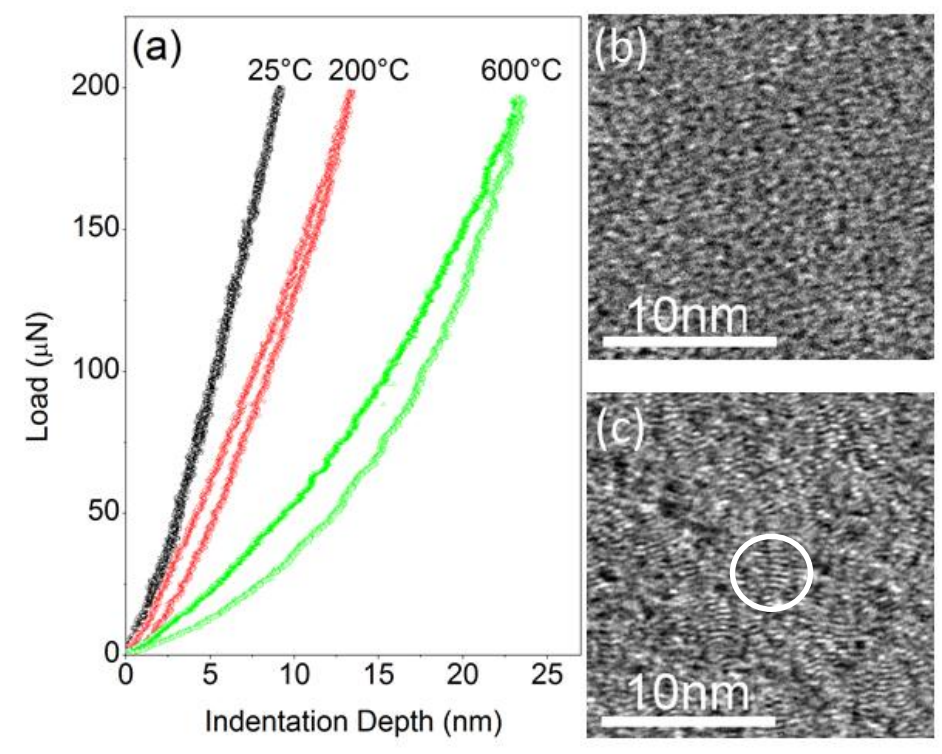

Fig. 3. (a) Typical load- displacement curves of carbon samples deposited at ion energy of 45 $\mathrm{eV}$ and substrate temperatures 25,200 and $600{ }^{\circ} \mathrm{C}$. Plan view TEM images of the samples deposited at 200 and $600{ }^{\circ} \mathrm{C}$ are shown in (b) and (c). A small graphitic region is circled in (c).

The load-unload curve exhibited by the sample prepared with $45 \mathrm{eV}$ ion energy at $25^{\circ} \mathrm{C}$ (Fig. 3a) is consistent with high modulus ta-C which has a dense $\mathrm{sp}^{3}$ bonded amorphous microstructure (not shown). Plan view TEM images of the samples deposited at elevated temperatures are shown in Fig. $3 \mathrm{~b}$ and c. The microstructure of the sample prepared at $200^{\circ} \mathrm{C}$ is still largely amorphous but with lower density $\left(2.5 \mathrm{~g} / \mathrm{cm}^{3}\right)$, this sample contains more graphite-like bonds and therefore has a lower modulus, as shown in its load-unload behaviour (Fig. 3a). The load-unload hysteresis can be explained by deformation occurring in the $\mathrm{sp}^{2}$ bonded component of the film. In the film deposited at $600^{\circ} \mathrm{C}$ (Fig. 3c), small graphitic regions are clearly discernible (see circled region in Fig. 3c). 
These graphitic regions are likely to be responsible for the increased load-unload hysteresis. Due to their small size $(<2 \mathrm{~nm})$, however, they do not permanently deform and the film completely recovers. The small size of these graphitic regions is associated with the small thermal spike volumes of $45 \mathrm{eV}$ impacts. The diameter of the molten volume of such a spike is expected to be less than $2 \mathrm{~nm}$ [37], consistent with our observations.

Fig. 4a shows the load-displacement curves from samples deposited with $600 \mathrm{eV}$ ion energy and deposition temperatures of 25,400 and $600^{\circ} \mathrm{C}$. All three exhibit larger hysteresis compared to the samples prepared at lower energies (Fig 3a). In addition, for these samples the recovery is not complete after the load- unload cycle, resulting in a residual indent impression. The samples deposited at 400 and $600^{\circ} \mathrm{C}$ contain larger graphite-like regions, up to $10 \mathrm{~nm}$ in size (Fig. $4 \mathrm{~b}$ and c). The larger correlated regions are consistent with the larger thermal spike volumes produced by $600 \mathrm{eV}$ impacts. These larger graphite-like structures are more readily deformed due to slippage over larger distances and do not recover in the $20 \mathrm{~s}$ cycle time. 


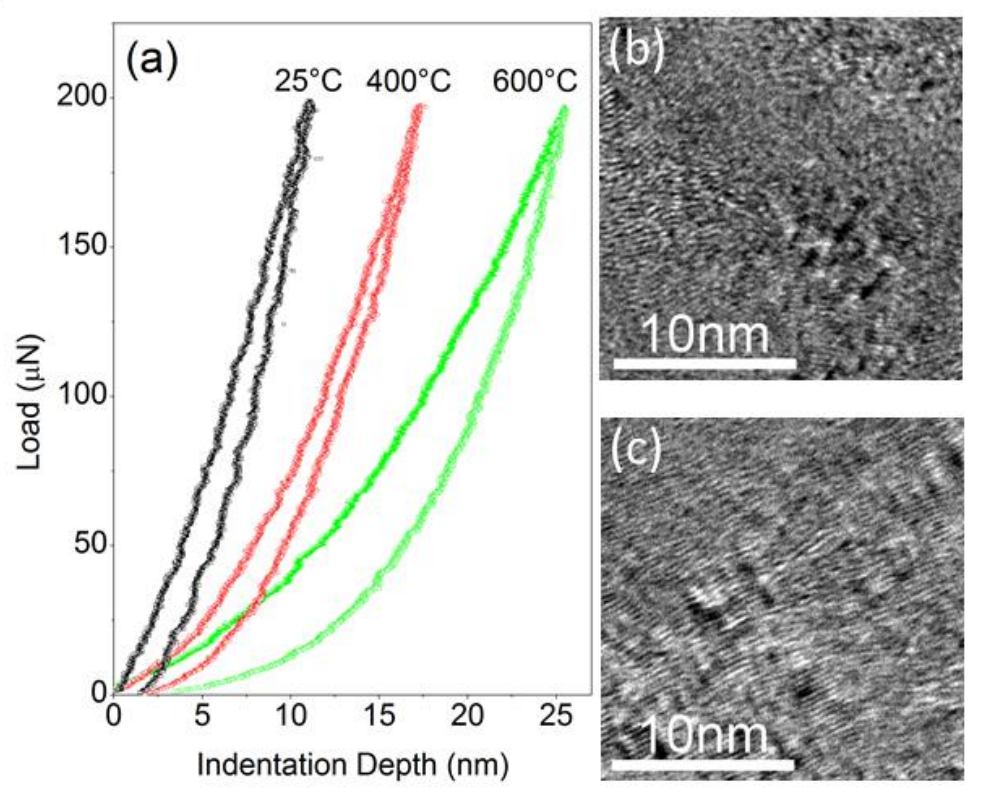

Fig. 4. (a) Typical load- displacement curves of samples prepared with $600 \mathrm{eV}$ ion energy and with deposition temperatures of 25,400 and $600^{\circ} \mathrm{C}$. The microstructure of the films deposited at 400 and $600^{\circ} \mathrm{C}$ are shown in the TEM images (b) and (c) respectively.

A cross-sectional TEM image of a sample prepared at $600^{\circ} \mathrm{C}$ and $600 \mathrm{eV}$ is shown in Fig. 5a with the substrate visible at the bottom of the image. A selected area diffraction pattern from the film is shown in Fig. 5b. The intense spots aligned parallel to the substrate have been indexed to $\{002\}$ graphite reflections. These indicate that the film contains oriented graphitelike regions with layers aligned perpendicular to the substrate. This type of preferred orientation has been reported previously and was attributed to a response of the anisotropic graphite crystallites to the compressive biaxial stress field present during growth at higher energies ( > $600 \mathrm{eV}$ ) and at elevated temperatures beginning from low energies [16, 31]. These oriented graphitic regions are present through the full depth of the sample, as shown in the dark-field image taken from one of the $\{002\}$ reflections (Fig. 5b). 
The large indent impression observed after a load-unload cycle shows this microstructure is susceptible to permanent deformation.

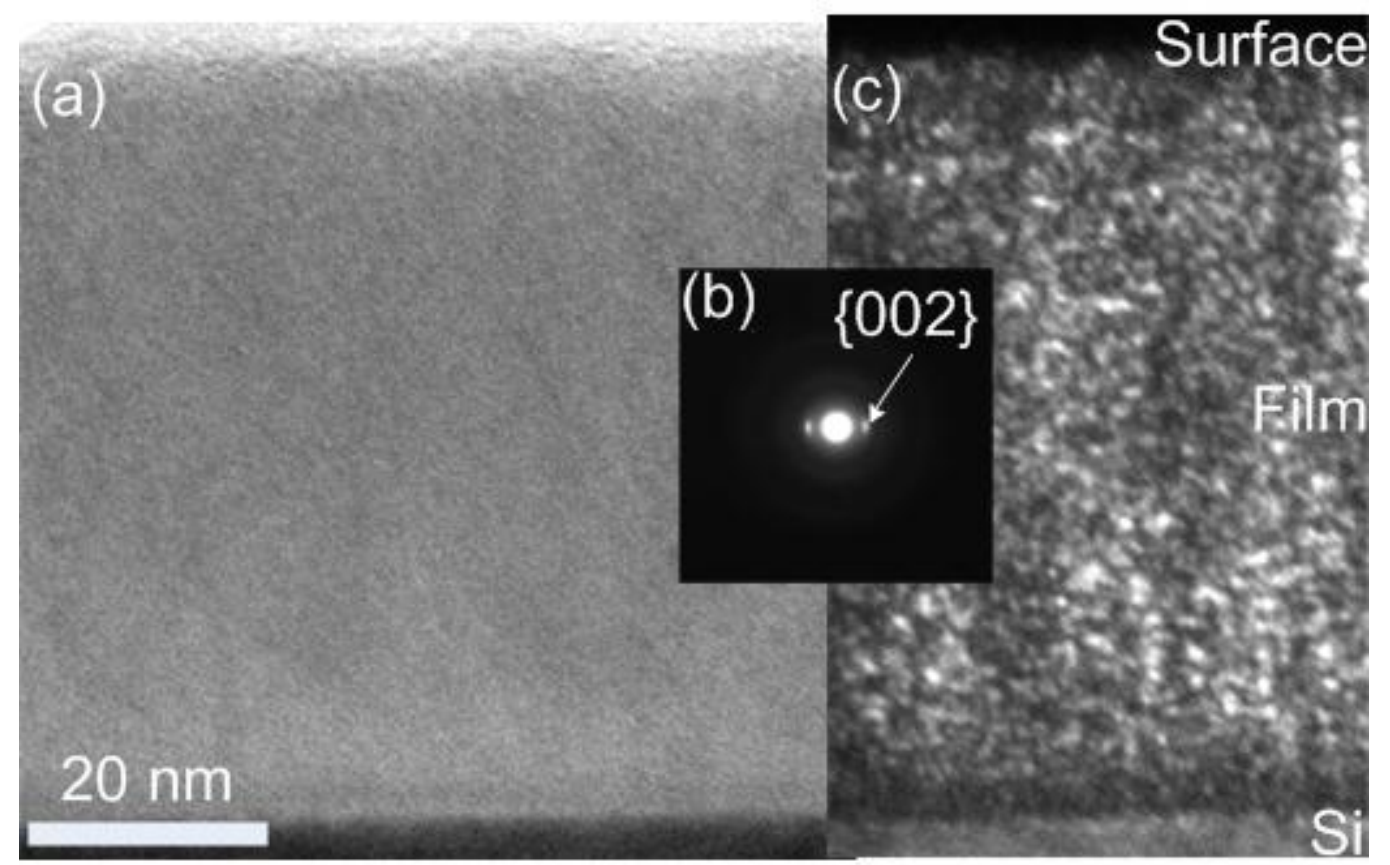

Fig. 5. (a) The cross-sectional TEM image of a sample prepared at $600{ }^{\circ} \mathrm{C}$ and $600 \mathrm{eV}$, with the substrate at the bottom. (b) A selected area diffraction pattern from the film, with the bright diffraction spots indexed to graphite. (c) The dark field image from the same area as (a) collected from one of the $\{002\}$ diffraction spots.

Fig. 6 shows contour plots of (a) $E_{r}$, (b) the residual indent impression after a complete cycle and (c) $E_{d}$ for a large number of samples with a range of deposition temperatures and ion energies. In nanoindentation measurements, the hardness is usually defined by the maximum load and the projected area of the residual indent impression [22, 25]. As mentioned earlier, the almost full recovery observed following indentation of most of these samples prevented the application of this standard approach. Films with the highest $\mathrm{E}_{\mathrm{r}}$ of up to $\sim 400 \mathrm{GPa}$ are formed under conditions which produce the highest density (Fig. 2). This value is in the range 350-700 GPa previously reported for ta-C [11]. Generally, as the density of the films reduces so does $\mathrm{E}_{\mathrm{r}}$, consistent with previous studies $[4,38,39]$. However, this is 
not always the case. At high deposition temperatures and/or energies, films with similar densities (the green region corresponding to $\sim 2.2 \mathrm{~g} / \mathrm{cm}^{3}$ shown in Fig. 2) have different $\mathrm{E}_{\mathrm{r}}$.

These changes in $E_{r}$ are attributed to the different film microstructures as discussed above. The samples deposited at elevated temperatures with significant levels of $\mathrm{sp}^{2}$ bonding exhibit the lowest $\mathrm{E}_{\mathrm{r}}$. The plastic deformation as evidenced by the residual indent impression (Fig. $5 b$ ) is larger at high energies due to the larger thermal spikes creating larger correlation distances. This measure does not follow the same trend as $\mathrm{E}_{\mathrm{r}}$. Instead, a maximum in residual indent impression occurs at the highest temperatures and energies, while $E_{r}$ is constant with energy at the highest temperature. This behaviour is attributed to the increasing crystalline volume fraction. Similarly, $\mathrm{E}_{\mathrm{d}}$ is highest in samples prepared at both high temperatures and high energies, where the microstructures contain the largest ordered graphitic regions and thus follow the same trend as the residual impressions. 


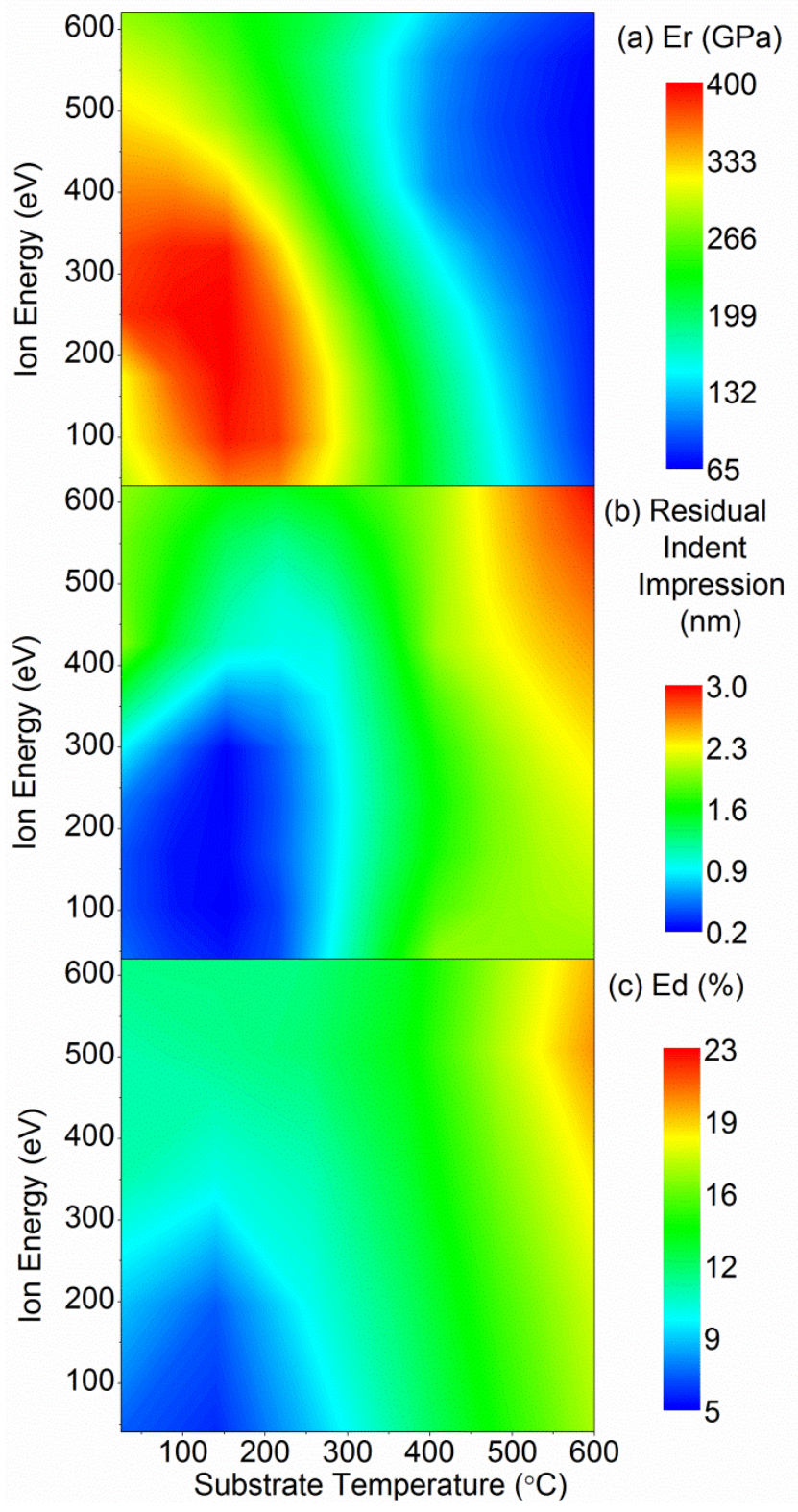

Fig. 6. (a) The reduced elastic moduli $\left(E_{r}\right)$, (b) residual impression after indentation and (c) energy dissipation $\left(E_{d}\right)$ measured in carbon films deposited with different average ion energy and substrate temperature. 
Fig. 7 shows the experimental and simulated load-displacement curves from four carbon films with different indentation behaviours. These simulations allow the Young's modulus (E) of the films to be determined. This is different from the reduced elastic modulus $\left(\mathrm{E}_{\mathrm{r}}\right)$ shown in Fig. 6a which is the composite modulus of the indenter and specimen. Fig. 7a shows the result for a high modulus ta-C sample prepared at an energy of $45 \mathrm{eV}$ and a substrate temperature of $25^{\circ} \mathrm{C}$. The correspondence between the simulated and experimental curves shows that the film exhibits elastic behaviour even at the highest load. E of $670 \mathrm{GPa}$ and $v$ of 0.12 were found to provide the best fit with experiment. These values are similar to those reported by Ferrari [11] for ta-C measured using surface acoustic waves (Brillouin scattering). To put this value in perspective, the values of $\mathrm{E}$ and $v$ of polycrystalline cubic boron nitride (one of the highest modulus non-crystalline material known) are 630- $770 \mathrm{GPa}$ and $0.14-0.18$ respectively [40, 41]. Fig. $7 \mathrm{~b}$ shows that the sample deposited at $45 \mathrm{eV}$ and $200{ }^{\circ} \mathrm{C}$ (amorphous with a density of $\sim 2.3 \mathrm{~g} / \mathrm{cm}^{3}$, see Fig. 3b) deviates from elastic behaviour at the point indicated by "A". E determined from the best fit of the FEM model was 235 GPa and $v$ is 0.17 . These values reflect behaviour for a lower density disordered carbon. Fig. 7c and $\mathrm{d}$ show results for films deposited at $600{ }^{\circ} \mathrm{C}, 45 \mathrm{eV}$ and $600^{\circ} \mathrm{C}, 620 \mathrm{eV}$ respectively. The films exhibit increasing departures from purely elastic behaviour at lower loads (indicated by the points "A"). The best fit to the elastic portions of the curves gave E of 85 and $75 \mathrm{GPa}$, respectively. These lower values of E reflect the high levels of graphitic order in these films (see Fig. 3c and Fig. 4c).

There is a noticeable difference in the behaviours of the films in Fig. 7c and 7d. The film in Fig. 7c completely recovers from deformation even though there is considerable energy dissipation $E_{d}$. The ability of this film to recover all of the plastic flow (anelasticity) is remarkable and similar to that observed previously for glassy carbon $[8,9]$. We attribute this to the shape- memory of graphene sheets that are intertwined but do not form extended 
regions resembling graphite where permanent slippage is likely to occur. This latter behaviour is well illustrated in the TEM image of Fig. 3c, which has larger graphitic regions, resulting in the residual impression observed following indentation evident in Fig. 7d.

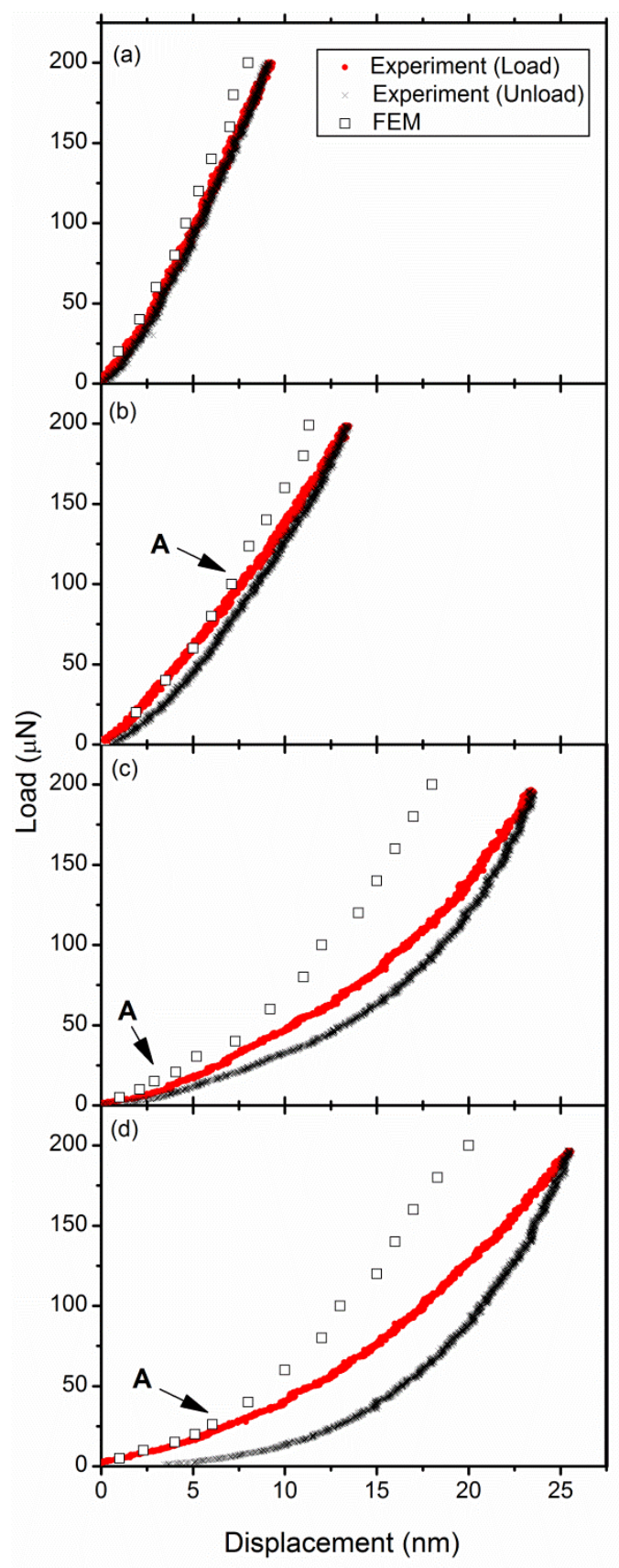

Fig. 7. Load-displacement characteristics obtained from non-crystalline carbon films deposited at (a) $25{ }^{\circ} \mathrm{C}, 45 \mathrm{eV}$ (b) $200{ }^{\circ} \mathrm{C}, 45 \mathrm{eV}$ (c) $600{ }^{\circ} \mathrm{C}, 45 \mathrm{eV}$ and (d) $600{ }^{\circ} \mathrm{C}, 620 \mathrm{eV}$ 
compared with simulated characteristics. The point ' $\mathrm{A}$ ' indicates increasing departures from purely elastic behaviour at lower loads.

\section{Conclusion}

We have investigated the indention behaviour of carbon films prepared using energetic deposition at energies from 25 to $600 \mathrm{eV}$ and temperatures from 25 to $600{ }^{\circ} \mathrm{C}$. There is a wide range of indentation behaviour, even in films at the same densities. The behaviour is elastic in ta-C deposited with intermediate bias and low to medium temperature. Using finite element modelling, ta-C was found to have an $\mathrm{E}$ of $670 \mathrm{GPa}$, confirming that it has one of the highest Young's moduli known. The preparation of samples at low energy and moderate to high temperature results in anelastic behaviour, characterised by plastic deformation under load and full recovery after indentation. In contrast, samples deposited at high energies over the full range of growth temperatures exhibit plastic behaviour without full recovery. These effects can all be explained in terms of the microstructure resulting from different thermal spike volumes at the different energies and the degree of graphite-like ordering determined by the growth temperature.

\section{Acknowledgements}

The authors acknowledge the scientific and technical assistance of the Microscopy and Microanalysis Facility at RMIT University (RMMF). Dr. Bianca Haberl gratefully acknowledges current funding from an Alvin M. Weinberg Fellowship (ORNL) and the Spallation Neutron Source (ORNL), sponsored by the U.S. Department of Energy, Office of Basic Energy Sciences. The authors also thank Prof. Yeshayahu (Shay) Lifshitz for useful discussions. 


\section{References}

1. Bull, S.J., Tribology of carbon coatings: DLC, diamond and beyond. Diamond and Related Materials, 1995. 4(5-6): p. 827-836.

2. Roy, R.K. and K.-R. Lee, Biomedical applications of diamond-like carbon coatings: A review. Journal of Biomedical Materials Research Part B: Applied Biomaterials, 2007. 83B(1): p. $72-$ 84.

3. Pierson, H.O., Handbook of carbon, graphite, diamonds and fullerenes: processing, properties and applications. 2012: William Andrew.

4. Charitidis, C.A., Nanomechanical and nanotribological properties of carbon-based thin films: A review. International Journal of Refractory Metals and Hard Materials, 2010. 28(1): p. 5170.

5. Field, S.K., M. Jarratt, and D.G. Teer, Tribological properties of graphite-like and diamond-like carbon coatings. Tribology International, 2004. 37(11-12): p. 949-956.

6. Oguri, K. and T. Arai, Tribological properties and characterization of diamond-like carbon coatings with silicon prepared by plasma-assisted chemical vapour deposition. Surface and Coatings Technology, 1991. 47(1-3): p. 710-721.

7. McKenzie, D.R., D. Muller, and B.A. Pailthorpe, Compressive-stress-induced formation of thin-film tetrahedral amorphous carbon. Physical Review Letters, 1991. 67(6): p. 773-776.

8. Iwashita, N., J. Field, and M. Swain, Indentation hysteresis of glassy carbon materials. Philosophical magazine A, 2002. 82(10): p. 1873-1881.

9. Iwashita, N., et al., Elasto-plastic deformation of glass-like carbons heat-treated at different temperatures. Carbon, 2001. 39(10): p. 1525-1532.

10. Lee, C., et al., Measurement of the elastic properties and intrinsic strength of monolayer graphene. science, 2008. 321(5887): p. 385-388.

11. Ferrari, A.C., et al., Elastic constants of tetrahedral amorphous carbon films by surface Brillouin scattering. Applied Physics Letters, 1999. 75(13): p. 1893-1895.

12. Broitman, E., et al., Structural and mechanical properties of diamond-like carbon films deposited by direct current magnetron sputtering. Journal of Vacuum Science \&amp; Technology A, 2003. 21(4): p. 851-859.

13. Amelio, S., et al., Measurements of elastic properties of ultra-thin diamond-like carbon coatings using atomic force acoustic microscopy. Thin Solid Films, 2001. 392(1): p. 75-84.

14. Robertson, J., Properties and prospects for non-crystalline carbons. Journal of NonCrystalline Solids, 2002. 299-302, Part 2: p. 798-804.

15. Wei, Q., J. Sankar, and J. Narayan, Structure and properties of novel functional diamond-like carbon coatings produced by laser ablation. Surface and Coatings Technology, 2001. 146147: p. 250-257.

16. Lau, D.W.M., et al., The structural phases of non-crystalline carbon prepared by physical vapour deposition. Carbon, 2009. 47(14): p. 3263-3270.

17. Shi, X., et al., Transport of vacuum arc plasma through an off-plane double bend filtering duct. Thin Solid Films, 1999. 345(1): p. 1-6.

18. Haq, A.J., et al., Correlation of nanoindentation-induced deformation microstructures in diamondlike carbon coatings on silicon substrates with simulation studies. Journal of Materials Research, 2010. 25(05): p. 910-920. 
19. Haberl, B., et al., Phase transformations induced in relaxed amorphous silicon by indentation at room temperature. Applied Physics Letters, 2004. 85(23): p. 5559-5561.

20. Titantah, J.T. and D. Lamoen, Determination of the electron effective band mass in amorphous carbon from density-functional theory calculations. Physical Review B, 2004. 70(3): p. 033101.

21. Egerton, R., Electron energy-loss spectroscopy in the electron microscope. 2011: Springer Science \& Business Media.

22. Oliver, W.C. and G.M. Pharr, An improved technique for determining hardness and elastic modulus using load and displacement sensing indentation experiments. Journal of Materials Research, 1992. 7(06): p. 1564-1583.

23. Chen, X. and J.J. Vlassak, Numerical study on the measurement of thin film mechanical properties by means of nanoindentation. Journal of Materials Research, 2001. 16(10): p. 2974-2982.

24. Sakai, M., The Meyer hardness: A measure for plasticity? Journal of Materials Research, 1999. 14(09): p. 3630-3639.

25. Pharr, G.M. and W.C. Oliver, Measurement of Thin Film Mechanical Properties Using Nanoindentation. MRS Bulletin, 1992. 17(07): p. 28-33.

26. Pharr, G.M., et al., Hardness, elastic modulus, and structure of very hard carbon films produced by cathodic-arc deposition with substrate pulse biasing. Applied Physics Letters, 1996. 68(6): p. 779-781.

27. D. Nix, W., Elastic and plastic properties of thin films on substrates: nanoindentation techniques. Materials Science and Engineering: A, 1997. 234-236(0): p. 37-44.

28. Kocer, C., An automated incremental finite element study of Hertzian cone crack growth. Finite Elements in Analysis and Design, 2003. 39(7): p. 639-660.

29. Spear, Synthetic Diamond - Emerging CVD Science and Technology. 1994, NY: Wiley.

30. Zinkle, S.J. and L.L. Snead, Thermophysical and mechanical properties of SiC/SiC composites, in Other Information: PBD: Sep 1998; Related Information: Is Part Of Fusion materials semiannual progress report for the period ending June 30, 1998; Burn, G. [ed.] [comp.]; PB: 314 p.1998. p. Medium: X; Size: pp. 93-100.

31. Lau, D.W.M., et al., Abrupt Stress Induced Transformation in Amorphous Carbon Films with a Highly Conductive Transition Phase. Physical Review Letters, 2008. 100(17): p. 176101.

32. Fallon, P.J., et al., Properties of filtered-ion-beam-deposited diamondlike carbon as a function of ion energy. Physical Review B, 1993. 48(7): p. 4777-4782.

33. Chhowalla, M., et al., Influence of ion energy and substrate temperature on the optical and electronic properties of tetrahedral amorphous carbon (ta-C) films. Journal of applied physics, 1997. 81(1): p. 139-145.

34. Koskinen, J., J.-P. Hirvonen, and J. Keränen, Effect of deposition temperature and growth rate on the bond structure of hydrogen free carbon films. Journal of applied physics, 1998. 84(1): p. 648-650.

35. Gago, R., et al., Evolution of $s p 2$ networks with substrate temperature in amorphous carbon films: Experiment and theory. Physical Review B, 2005. 72(1): p. 014120.

36. Jungk, J.M., et al., Indentation fracture toughness and acoustic energy release in tetrahedral amorphous carbon diamond-like thin films. Acta Materialia, 2006. 54(15): p. 4043-4052.

37. Marks, N.A., Evidence for subpicosecond thermal spikes in the formation of tetrahedral amorphous carbon. Physical Review B, 1997. 56(5): p. 2441-2446.

38. Beghi, M.G., et al., Bonding and mechanical properties of ultrathin diamond-like carbon films. Applied Physics Letters, 2002. 81(20): p. 3804-3806.

39. Philip, J., et al., Elastic, mechanical, and thermal properties of nanocrystalline diamond films. Journal of Applied Physics, 2003. 93(4): p. 2164-2171. 
40. D'Evelyn, M.P. and T. Taniguchi, Elastic properties of translucent polycrystalline cubic boron nitride as characterized by the dynamic resonance method. Diamond and Related Materials, 1999. 8(8-9): p. 1522-1526.

41. Grimsditch, M., E.S. Zouboulis, and A. Polian, Elastic constants of boron nitride. Journal of Applied Physics, 1994. 76(2): p. 832-834. 